\title{
ANALISIS PERUMUSAN STRATEGI BISNIS PADA PT SAMUDERA NUSANTARA LOGISTINDO
}

\author{
Engkos Achmad Kuncoro \\ Jurusan Manajemen, Fakultas Ekonomi dan Bisnis, Universitas Bina Nusantara, \\ Jln. K.H. Syahdan No. 9, Palmerah, Jakarta Barat 11480 \\ eak@binus.edu
}

\begin{abstract}
PT Samudra Nusantara Logistindo (PT SNL) is a company engaged in international cargo transportation services (international freight forwarder). Purpose of this study is to analyze the internal and external conditions and formulating business strategy and in order to gain competitive advantage for companies. The research method used in this research is a qualitative descriptive method research types such as of case studies. We have used Data Collection Techniques using interviews, surveys and questionnaires provided by the relevant parties in the company. These obtained data has been analyzed using a matrix IFE, EFE, CPM, TOWS, IE, SPACE, Grand Strategy and QSPM. The results of the IFE Matrix 2.885 and EFE Matrix are 2.623. The Result of the following Matrixes TOWS, SPACE, IE, Grand Strategy alternatives that can be applied in the company will be market penetration and product development strategy. The final results of this study concluded that the recommendation or proposal of an appropriate business strategy for the company based on the results obtained through a matrix of data processing is QSPM Market development strategy are then followed by the product development.
\end{abstract}

Keywords: strategic management, SWOT analysis, market development, product development

\begin{abstract}
ABSTRAK
PT Samudera Nusantara Logistindo (PT SNL) adalah perusahaan yang bergerak dalam bidang jasa transportasi barang internasional (international freight forwarder). Tujuan dari penelitian ini adalah untuk menganalisis kondisi internal dan eksternal perusahaan dan menyusun formulasi strategi bisnis guna memperoleh keunggulan bersaing bagi perusahaan. Metode penelitian yang digunakan dalam penelitian ini adalah metode deskriptif kualitatif dengan jenis penelitian studi kasus. Teknik pengumpulan data menggunakan wawancara, survey dan kuesioner yang dilakukan terhadap pihak-pihak terkait di dalam perusahaan. Data-data yang telah diperoleh tersebut dianalisis menggunakan Matriks IFE, EFE, CPM, TOWS, IE, SPACE, Grand Strategy dan QSPM. Hasil dari Matriks IFE sebesar 2,885 dan Matriks EFE sebesar 2,623. Hasil analisis Matriks TOWS, SPACE, IE, Grand Strategy menunjukkan alternatif yang dapat diterapkan perusahaan adalah strategi penetrasi pasar dan pengembangan produk. Hasil akhir penelitian ini menyimpulkan bahwa rekomendasi atau usulan strategi bisnis yang tepat bagi perusahaan didapat berdasarkan hasil pengolahan data melalui Matriks QSPM adalah strategi pengembangan pasar (market development) yang lalu diikuti oleh pengembangan produk (product development).
\end{abstract}

Kata kunci: manajemen strategi, analisis SWOT, pengembangan pasar, pengembangan produk 


\section{PENDAHULUAN}

\section{Latar Belakang}

Dalam beberapa tahun belakangan ini hingga sekarang dunia bisnis telah memasuki era revolusi informasi yang ditandai dengan perubahan lingkungan dengan karakteristik yang jauh berbeda dari era-era sebelumnya. Dalam era revolusi industri, keunggulan daya saing suatu entitas usaha ditentukan oleh efisiensi dalam alokasi sumber daya atau asset berwujud (tangible resources/assets) yang mudah dijabarkan dalam dimensi keuangan. Sebaliknya, dalam era revolusi informasi, keunggulan daya saing suatu entitas usaha sangat tergantung pada kemampuannya untuk memobilisasi dan mengeksploitasi sumber daya atau asset tak berwujud (intangible resources/assets) yang tidak mudah dijabarkan dalam dimensi keuangan (Prakarsa dalam Yuwono, 2007).

Menurut Porter (1996), mengelola strategi adalah berbeda dengan mengelola operasi. Tetapi keduanya sangat penting, dan perlu diintegrasikan. Strategi visioner yang tidak dikaitkan dengan keunggulan proses operasi dan tata kelola (governance) tidak akan dapat diterapkan. Sebaliknya, keunggulan operasi mungkin bisa menurunkan biaya, memperbaiki mutu dan mengurangi jumlah proses dan waktu tunggu, tetapi tanpa visi dan panduan dari strategi, perusahaan tidak mungkin menikmati kesuksesan yang berkesinambungan hanya dengan perbaikan operasi semata (Kaplan \& Norton, 2008). Perkembangan kondisi eksternal yang dinamis dan situasi internal dalam perusahaan yang ingin terus bergerak maju telah menuntut perusahaan untuk merumuskan strategi bisnisnya dengan baik dan bisa memandu implementasinya sehingga berhasil mewujudkan visi dan misi yang telah dicanangkan.

Di tengah pergerakan bisnis barang dan jasa, data menunjukkan bahwa pertumbuhan bisnis jasa telah mengalami peningkatan yang tinggi, seperti yang dipublikasikan oleh Biro Pusat Statistik (2010) bahwa laju pertumbuhan Produk Domestik Bruto (PDB) Indonesia menurut lapangan usaha dari sektor jasa mengalami kenaikan sebesar 4,2 \% dari triwulan I sampai dengan triwulan III tahun 2009 jika dibandingkan dengan triwulan yang sama pada tahun 2008. Dari beragamnya bisnis jasa yang ada maka salah satu yang terpenting adalah bisnis jasa pengangkutan. Hal ini di sebabkan jasa pengangkutan sangat berperan dalam menunjang bisnis internasional.

Pengangkutan merupakan kegiatan pemindahan barang-barang dan manusia dari satu tempat asal ke tempat tujuan. Barang-barang harus diangkut dari satu daerah ke daerah lainnya dalam satu negara atau antar negara, agar barang tersebut dapat memenuhi kebutuhan hidup manusia. Berkat kemajuan dalam dunia pengangkutan, jarak antara daerah di dunia ini dirasakan menjadi lebih dekat, dunia makin transparan dan globalisasi dalam segala bidang kehidupan. Pengangkutan telah menjadi salah satu unsur yang menentukan guna menjamin perkembangan ekonomi di masyarakat. Bertambah maju tingkat perekonomian bertambah penting pula peranan pengangkutan ini. Pengangkutan tidak lagi dipandang sebagai sektor yang memberikan pelayanan semata-mata, tetapi telah menjadi partner dari kegiatan-kegiatan ekononi dan bisnis.

Jasa pengiriman barang di Indonesia secara tidak resmi telah ada sejak tahun 1977, namun baru pada 16 Juli 1980 diberikan ijin operasi untuk 15 perusahaan jasa pengiriman oleh Departemen Perdagangan. Sejak itulah usaha jasa pengiriman di Indonesia berkembang pesat dan ditandai dengan berdirinya INFA (Indonesian National Freight Forwarder Association) yang resmi diakui oleh pemerintah Indonesia dan terdaftar sebagai anggota IATA (International Air Transport Association).

Bisnis forwarding Indonesia sangat dipengaruhi oleh kinerja export dalam negeri dan fluktuasi perdagangan internasional. Kinerja export Indonesia di tahun 2010 diproyeksikan mengalami kenaikan setelah mengalami penurunan di tahun 2009. Hal ini disebabkan adanya penurunan permintaan barang 
export sebagai dampak dari krisis global yang sangat berpengaruh terhadap permintaan pasar internasional. Melemahnya kinerja export disebabkan oleh permintaan produk export yang berkurang dan atau menurunnya harga komoditas export. Apabila penurunan ini berkelanjutan, maka kemungkinan terjadi penurunan cadangan devisa. Adapun batas aman nilai cadangan devisa adalah empat bulan export dan pembayaran kewajiban atau kurang lebih US\$ 50 milyar.

Dengan kondisi perkembangan perekonomian belakangan ini, banyak perusahaan baru bermunculan tetapi banyak pula perusahaan lain berguguran. Hal tersebut menunjukkan adanya peluang bisnis yang menjanjikan bagi para pemain lama ataupun baru untuk menekuni bisnis ini, salah satunya adalah PT Samudera Nusantara Logistindo (PT SNL). Aktivitas bisnis PT SNL telah dirintis sejak awal tahun 2000-an dan telah menunjukkan kinerja yang positif dalam beberapa tahun belakangan ini. Namun, ketatnya persaingan bisnis yang ada menuntut PT SNL untuk mengantisipasinya melalui perumusan strategic planning yang memungkinkan perusahaan untuk terus tumbuh dan berkembang di masa yang akan datang.

Penerapan manajemen strategis yang baik diawali dengan formulasi, yaitu proses pembuatan suatu visi dan misi, mengenali ancaman dan peluang suatu organisasi, menentukan kekuatan dan kelemahan organisasi, membangun tujuan jangka panjang, merumuskan alternatif strategi, dan memilih strategi tertentu yang akan dilaksanakan. Setelah formulasi ditetapkan, berikutnya perusahaan harus mengimplementasikan formulasi strategi manajemen tersebut ke dalam proses bisnis perusahaan. Setelah strategi manajemen diimplementasikan, maka perusahaan harus mengevaluasi hasil implementasi formulasi strategi manajemen tersebut, apakah sudah sesuai untuk diterapkan dalam proses bisnis perusahaan atau tidak. Apabila sesuai, tentu saja strategi manajemen akan meningkatkan hasil kinerja perusahaan, begitu juga sebaliknya.

Pengembangan perusahaan melalui manajemen strategi yang baik sangat penting agar perusahaan dapat mengevaluasi kinerja keseluruhan perusahaan secara berkala sehingga dapat diketahui faktor-faktor apa yang menghambat kemajuan perusahaan dan dapat dicari penanggulangannya, juga untuk mencari faktor-faktor apa saja yang merupakan kekuatan perusahaan agar dapat dikembangkan bagi keuntungan dan kekuatan bersaing perusahaan di industri jasa pengiriman barang. Persaingan yang bersifat global dan tajam dalam dunia logistik menyebabkan banyak perusahaan jatuh bangkrut karena kalah bersaing, kondisi ini mengharuskan perusahaan memiliki daya saing yang tinggi agar dapat menjadi perusahaan yang kuat, sehingga dapat bersaing dengan perusahaan sejenis dan menjadi yang terbaik diantara perusahaan lainnya.

Berdasarkan uraian di atas, identifikasi masalah yang dapat dirumuskan adalah: "bagaimana mengidentifikasi kondisi faktor internal (kekuatan dan kelemahan) dan faktor eksternal (peluang dan ancaman) PT SNL", dan "bagaimana memformulasikan strategi bisnis untuk PT SNL dalam meningkatkan daya saing perusahaan.”

Sedangkan tujuan penelitian ini adalah: pertama, untuk mengidentifikasi kondisi faktor internal (kekuatan dan kelemahan) dan kondisi faktor eksternal (peluang dan ancaman) perusahaan; kedua, merumuskan strategi bisnis perusahaan dan memberikan usulan atau rekomendasi strategi bisnis yang digunakan perusahaan. Hasil kajian diharapkan dijadikan tolak ukur atau pijakan untuk menyusun suatu perencanaan yang baik di masa akan datang dan merupakan suatu analisis yang efektif bagi perkembangan perusahaan dan dapat dijadikan sebagai masukan konstruktif pedoman dalam penyusunan strategi perusahaan di masa yang akan datang.

\section{Tinjauan Pustaka}

Dewasa ini, setiap manager semua jenis organisasi senantiasa dituntut untuk berfikir secara strategis mengenai posisi dan kemampuan kompetitif organisasinya dan pengaruh perkembangan 
lingkungan luar terhadap organisasi. Manager atau pemimpin organisasi harus memahami betul-betul bisnis dan tugasnya, sehingga pada saatnya akan mengetahui strategi yang harus dibuat dalam menghadapi suatu perubahan atau situasi tertentu. Strategi adalah suatu alat untuk mencapai tujuan jangka panjang (David, 2009: 15). Dalam perumusan strategi, faktor-faktor yang harus dipertimbangkan adalah kondisi internal (kekuatan dan kelemahan) dan kondisi eksternal (peluang dan ancaman) yang dihadapi oleh perusahaan. Hansen dan Smith (David, 2006: 225) pernah menjelaskan bahwa perencanaan strategi melibatkan "pilihan yang membahayakan sumber daya" dan "trade-off yang mengorbankan peluang", artinya dalam menetapkan strategi menanggung resiko yang besar sehingga membutuhkan keputusan manajemen tingkat atas dan prioritas harus ditetapkan.

Menurut Rangkuti (1998: 3), suatu perusahaan dapat mengembangkan strategi untuk mengatasi ancaman eksternal dan merebut peluang yang ada. Proses analisis, perumusan dan evaluasi strategi-strategi itu disebut perencanaan strategis. Tujuan utama perencanaan strategis adalah agar perusahaan dapat melihat secara obyektif kondisi-kondisi internal dan eksternal, sehingga perusahaan dapat mengantisipasi perubahan lingkungan eksternal.

Menurut David (2009: 6), proses manajemen strategis terdiri dari tiga tahap, yaitu perumusan strategi (strategic formulation), implementasi strategi (strategic implementation) dan evaluasi strategi (strategic evaluation). Perumusan strategi termasuk mengembangkan misi bisnis, mengenali peluang dan ancaman eksternal perusahaan, menetapkan kekuatan dan kelemahan internal, menetapkan tujuan jangka panjang, menghasilkan strategi alternatif, dan memilih strategi tertentu untuk dilaksanakan. Implementasi Strategi menuntut perusahaan menetapkan obyektif tahunan, memperlengkapi dengan kebijakan, memotivasi karyawan, dan mengalokasikan sumber daya sehingga strategi yang dirumuskan dapat dilaksanakan; implementasi strategi termasuk mengembangkan budaya mendukung strategi, menciptakan struktur organisasi yang efektif, mengubah arah usaha pemasaran, menyiapkan anggaran, mengembangkan dan memanfaatkan sistem informasi, dan menghubungkan kompensasi karyawan dengan prestasi organisasi. Evaluasi Strategi adalah tahap akhir dalam manajemen strategis. Para manager sangat perlu mengetahui kapan strategi tertentu tidak berfungsi dengan baik, evaluasi strategi terutama berarti usaha untuk memperoleh informasi ini.

Prosedur yang ditempuh dalam penyusunan Rencana Strategis ini meliputi: metode pengumpulan data, analisis lingkungan eksternal (peluang dan ancaman) dan analisis lingkungan internal (kekuatan dan kelemahan). Analisis lingkungan eksternal (peluang dan ancaman) menurut Hit (2001: 52-83), menjabarkan bahwa. Pertama, peluang (opportunities) adalah kondisi-kondisi dalam lingkungan umum yang dapat membantu organisasi mencapai daya saingnya. Kedua, ancaman (threats) adalah kondisi-kondisi dalam lingkungan umum yang dapat mengganggu usaha organisasi dalam mencapai daya saing strategis. Tujuan audit eksternal adalah untuk mengembangkan daftar terbatas peluang yang dapat dimanfaatkan oleh organisasi dan ancaman yang harus dihindari. Komponen analisis eksternal terdiri dari: scanning, mengidentifikasi petunjuk awal dari perubahan dan kecenderungan lingkungan; monitoring, mendeteksi arti melalui observasi terus menerus atas perubahan dan kecenderungan lingkungan; forecasting, mengembangkan proyeksi atas hasil yang diantisipasi berdasarkan perubahan dan kecenderugan yang dimonitor; assessing, menentukan waktu dan pentingnya perubahan serta kecenderungan lingkungan untuk strategi organisasi dan manajemennya. Selanjutnya menurut Hit (2001: 99-129), analisis lingkungan internal (kekuatan dan kelemahan), terdiri dari: kekuatan (strengths) yakni sumber daya, ketrampilan atau keunggulankeunggulan lain relatif terhadap pesaing dan kebutuhan masyarakat yang dilayani atau ingin dilayani oleh organisasi; lelemahan (weakness) yakni keterbatasan atau kekurangan dalam sumber daya, ketrampilan dan kapabilitas yang secara serius menghambat kinerja efektif organisasi. Kekuatan (distinctive competencies) adalah kekuatan suatu perusahaan yang tidak dapat dengan mudah ditandingi atau ditiru oleh pesaing, kemampuan yang berharga (valuable capabilities), kemampuan yang langka (rare capabilities), kemampuan yang tak dapat ditiru dengan sempurna (imperfectly imitable capabilities), kemampuan yang tak dapat diganti (nonsubstituable capabilities). 
Pendekatan lain yang dilakukan untuk mengevaluasi kekuatan dan kelemahan organisasi adalah melalui Resources-Based View (RBV) yang dikemukakan oleh Barney (2007: 127-162). Dalam pendekatan ini diuraikan kerangka kerja RBV, yaitu tentang inventarisasi sumber daya organisasi yang cukup bernilai (valuable), kelangkaan (rare) sehingga susah ditiru oleh perusahaan lain, sangat mahal jika ditiru (costly to imitate), dapat dieksploitasi oleh organisasi (exploited by organization) dan dampak dari persaiangan (competitive implications) jika sumber daya atau kapasitas organisasi tersebut didaya-gunakan sebagai kekuatan atau kelemahan.

Keunggulan bersaing adalah jantung dari kinerja perusahaan di dalam pasar yang bersaing. Tingginya persaingan bisnis menuntut setiap perusahaan untuk saling meluncurkan berbagai produk dan jasa yang memiliki daya saing yang tinggi. Perusahaan yang memiliki daya saing tinggi adalah perusahaan yang mampu meluncurkan produk baru secara cepat dengan periode waktu pengembangan produk yang singkat.

Menurut Lindelof dan Hans Lofsten (2004), dalam mengkaji konsep daya saing tidak terlepas dengan konsep strategi, karena strategi mengandung pengertian peningkatan daya saing (melalui pengembangan produk, kompetisi harga, pengembangan teknologi, menganalisis perilaku pesaing dan lainnya) yang dilakukan melalui positioning analisys di mana bisnis perusahaan akan dijalankan, di wilayah mana persaingan dan melakukan resource base-analysis bagaimana perusahaan akan bersaing. Sehingga daya saing (competitive advantage) didefinisikan oleh Grant (1991) sebagai hasil atas pemahaman secara menyeluruh dari aspek eskternal dan internal yang memberikan pengaruh kuat terhadap perusahaan. Selain itu, menurut Hitt (2001: 5) bahwa ketika perusahaan mengimplementasikan suatu strategi yang tidak dapat ditiru oleh perusahaan lain atau terlalu mahal untuk menirunya, perusahaan ini memiliki keunggulan persaingan bertahan atau dapat bertahan (sustained atau sustainable competitive advantage, selanjutnya disebut sebagai keunggulan persaingan).

Usaha untuk berubah, berorientasi untuk kepuasan pelanggan, serta meningkatkan kompetensi adalah usaha-usaha dalam rangka mempertahankan keunggulan kompetitif. Menurut D’Aveni dan Gunther (dalam Winardi, 2003: 19), posisi kompetitif suatu perusahaan, perlu dipertahankan selama mungkin. Tetapi perlu diingat, bahwa keunggulan hanya dapat bertahan sampai pihak pesaing meniru dan mengungguli keunggulan dan keunikan yang dimiliki oleh organisasi itu. Untuk menghadapi hal ini agar keunggulan dapat terus bertahan lama, D’Aveni menyarankan diciptakan suatu seri keunggulan temporer. Dengan seri keunggulan jangka pendek demikian, organisasi secara efektif menciptakan suatu keunggulan jangka panjang yang dapat bertahan di pasar. Keadaan ini menurut D’Aveni yang disebut hyper competitive.

Menurut Wheelen dan Hunger (2001: 7), strategi bersaing adalah strategi bisnis yang berfokus pada peningkatan posisi bersaing produk dan jasa perusahaan dalam industri atau segmen pasar tertentu yang dilayani perusahaan dan mengatasi masalah bagaimana perusahaan dan unit-unitnya dapat bersaing dalam bisnis dan industri. Lebih jauh Cravens (2008: 5) menjabarkan bahwa mengutip pendapat Day dan Wensley yang mengemukakan bahwa keunggulan bersaing seharusnya dipandang sebagai suatu proses dinamis daripada hasil akhir. Prosesnya terdiri atas sumber keunggulan, keunggulan posisi, dan prestasi hasil akhir suatu investasi laba untuk mempertahankan keunggulan. Sumber keunggulan bersaing itu adalah: keterampilan, sumber daya dan pengendalian yang superior.

Berkaitan dengan konsep kekuatan persaingan dalam industry, Porter (1998: 21) menjabarkan : The state of competition in an industry depends on five basic forces, threat of new entrants, bargaining power of suppliers, threat of substitute products or service, bargaining power of customers, the industry jockeying for position among current competitors. Untuk membangun keunggulan kompetitif berkelanjutan, menurut Walker (2007: 49) yang harus dilakukan oleh organisasi adalah dengan mengoptimalkan resources capabilities, yang terdiri dari value drivers, cost drivers, retaining customers dan preventing imitation. Value drivers dan cost drivers akan 
menciptakan posisi pasar yang kuat (superior market position), sedangkan retaining customers (mempertahankan konsumen) dan preventing imitation (mencegah imitasi produk) akan mendorong posisi pasar yang mampu bertahan (defendable market position). Jika kedua varianbel ini (superior market position dan defendable market position) mampu dipertahankan maka oleh organisasi pada gilirannya akan dapat mewujudkan keunggulan kompetitif berkelanjutan (sustainable competitive advantage).

Menurut David (2006: 282-284), teknik perumusan-strategi yang penting dapat diintegrasikan ke dalam kerangka kerja pengambilan keputusan tiga tahap yang terdiri dari tahap input, tahap pencocokan dan tahap keputusan. Tahap pertama, yaitu tahap input meringkas informasi dasar yang dibutuhkan untuk merumuskan strategi. Tahap kedua, yaitu tahap pencocokkan berfokus pada menciptakan alternatif strategi yang layak dengan mencocokkan faktor eksternal dan internal kunci. Tahap ketiga, yaitu tahap keputusan untuk mengevaluasi secara objektif alternatif-alternatif strategi yang layak dan dengan demikian, memberikan dasar tujuan untuk memilih strategi yang spesifik. Alat yang disajikan dalam kerangka kerja ini, dapat digunakan untuk semua ukuran dan tipe organisasi. Berikut ini adalah model kerangka kerja perumusan strategi tersebut.

Tabel 1 Model Kerangka Kerja Perumusan Strategi

\section{TAHAP 1 : TAHAP INPUT (INPUT STAGE)}

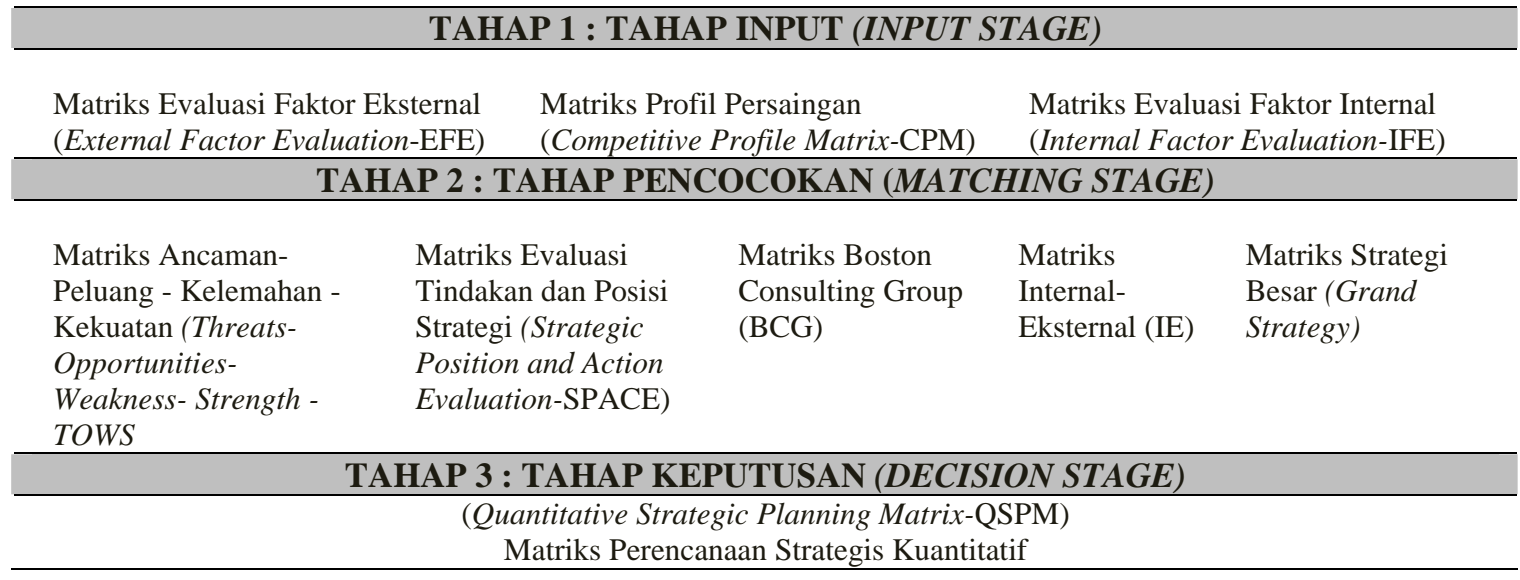

Sumber: David (2009:283)

\section{METODE PENELITIAN}

Metode penelitian yang digunakan adalah metode deskriptif kualitatif, yaitu metode yang bertujuan membantu memecahkan masalah yang bertujuan membantu memecahkan masalah yang terjadi pada masa sekarang serta berpusat pada masalah yang actual. Metode deskriptif menggambarkan sifat sesuatu yang tengah berlangsung pada saat riset dilakukan dan memeriksa sebab-sebab dari suatu gejala tertentu (Taver dalam Sugiono, 2000: 22). Untuk merumuskan atau memformulasikan strategi, terdiri dari tiga tahap. Pertama, tahap masukan menggunakan matriks Evaluasi Faktor Eksternal/ External Factor Evaluation (EFE) dan matriks Evaluasi Faktor Internal/Internal Factor Evaluation (IFE). Kedua, tahap pencocokan menggunakan matriks TOWS (Threats, Opportunities, Weakness, Strength) dan matriks internal - eksternal (IE). Ketiga, tahap keputusan menggunakan matriks QSPM (Quantitative Strategic Planning Matrix-QSPM).

Penyusunan matriks IFE diperoleh dari evaluasi faktor-faktor internal perusahaan, sedangkan matriks EFE diperoleh dari evaluasi faktor-faktor eksternal perusahaan. Nilai bobot diperoleh dari perhitungan menggunakan AHP (Analytic Hierarchy Process), yaitu dengan dukungan software 
Expert Choice 2000 yang dilakukan setelah diketahui skala prioritas antar elemen-elemen faktor yang ada melalui pengisian kuesioner yang diberikan kepada Strategic Team PT SNL. Pembobotan diperlukan untuk mengetahui faktor kunci yang paling berpengaruh terhadap perusahaan. Untuk peringkat, nilainya juga ditentukan berdasarkan informasi dari hasil pengisian kuesioner yang diberikan kepada Strategic Team PT SNL. Dari hasil perhitungan bobot dan peringkat, maka akan diperoleh suatu nilai yang kemudian keseluruhan nilai akan dijumlahkan. Perusahaan biasanya dinilai memiliki kondisi internal yang cukup kuat dan sanggup mengatasi kelemahan, serta memiliki respon yang baik terhadap peluang maupun ancaman jika diperoleh nilai total akhir berada di atas nilai ratarata yaitu, 2,5.

\section{HASIL DAN PEMBAHASAN}

Hasil analisis terhadap faktor internal perusahaan, yaitu kekuatan (strength) dan kelemahan (weakness) dan faktor ekstenal meliputi peluang (opportunity) dan ancaman (threat) disajikan pada Tabel 2 dan 3 di bawah ini.

Tabel 2 Faktor-faktor Internal Kunci PT SNL

\begin{tabular}{lc}
\hline \multicolumn{1}{c}{ Faktor - faktor Internal Kunci PT SNL } & Skor \\
\hline Kekuatan : & \\
\hline 1. Kompetensi sumber daya manusia yang unggul dan berpengalaman & 3 \\
2. Kelengkapan jasa yang ditawarkan baik kargo laut, udara dan domestik & 4 \\
3. Produk jasa tailormade yang mengarah ke total logistics solution & 3 \\
4. Terdaftar dalam Gapeksi, IATA dan FIATA & 3 \\
5. Menjadi perwakilan beberapa agen shipping internasional & 4 \\
\hline Kelemahan : & 1 \\
\hline 1. Keterbatasan dana dalam penanganan tender potensial & 2 \\
2. Keterbatasan fasilitas infrastruktur & 2 \\
3. Kurangnya tenaga pemasaran dan dana untuk promosi & 2 \\
4. Pencapaian target penjualan import yang belum maksimal & 2 \\
\hline 5. Turn over staf yang tinggi di bagian operasional dan pemasaran & \\
\hline
\end{tabular}

Tabel 3 Hasil Wawancara Penilaian Skor Faktor Eksternal PT SNL

\begin{tabular}{lc}
\hline \multicolumn{1}{c}{ Faktor - faktor Eksternal Kunci PT SNL } & Skor \\
\hline Peluang : & 3 \\
\hline 1. Meningkatnya volume perdagangan global & 3 \\
2. Regulasi Pemerintah untuk meningkatkan volume export & 4 \\
3. Terbukanya peluang kerjasama dengan mitra internasional & 4 \\
4. Terbukanya peluang menjadi agen logistic perusahaan besar & 3 \\
5. Makin meningkatnya volume export dari usaha kecil dan menengah (UKM) & \\
Ancaman : & 2 \\
\hline 1. Mudahnya mendirikan usaha sejenis \& masuk dalam industri & 1 \\
\hline
\end{tabular}




\begin{tabular}{ll}
\hline 3. Banyaknya perusahaan asing yang membuka cabang di Indonesia & 1 \\
4. Infrastruktur dan sistem birokrasi di Indonesia yang kurang mendukung & 2 \\
5. Stabilitas politik antara Negara yang mengganggu bisnis transportasi & 1 \\
\hline
\end{tabular}

Matriks IFE menggunakan data dari hasil pembobotan dengan perhitungan menggunakan AHP (Analytic Hierarchy Process), yang hasilnya diuraikan pada tabel berikut ini.

Tabel 4 Matriks IFE

\begin{tabular}{|c|c|c|c|}
\hline Faktor - faktor Internal Kunci PT SNL & Bobot & Peringkat & $\begin{array}{l}\text { Rata-rata } \\
\text { tertimbang }\end{array}$ \\
\hline \multicolumn{4}{|l|}{ Kekuatan } \\
\hline $\begin{array}{l}\text { 1. Kompetensi sumber daya manusia yang unggul dan } \\
\text { berpengalaman }\end{array}$ & 0,068 & 3 & 0,203 \\
\hline $\begin{array}{l}\text { 2. Kelengkapan jasa yang ditawarkan baik kargo laut, udara dan } \\
\text { domestic }\end{array}$ & 0,224 & 4 & 0,895 \\
\hline \multirow[b]{2}{*}{$\begin{array}{l}\text { 3. Produk jasa tailormade yang mengarah ke total logistics solution } \\
\text { 4. Terdaftar dalam Gapeksi, IATA dan FIATA }\end{array}$} & 0,099 & 3 & 0,298 \\
\hline & 0,100 & 3 & 0,300 \\
\hline 5. Menjadi perwakilan beberapa agen shipping internasional & 0,161 & 4 & 0,644 \\
\hline \multicolumn{4}{|l|}{ Kelemahan : } \\
\hline \multicolumn{3}{|l|}{ 1. Keterbatasan dana dalam penanganan tender potensial } & 0,153 \\
\hline 2. Keterbatasan fasilitas infrastruktur & 0,056 & 2 & 0,112 \\
\hline 3. Kurangnya tenaga pemasaran dan dana untuk promosi & 0,051 & 2 & 0,102 \\
\hline \multirow{2}{*}{ 4. Pencapaian target penjualan import yang belum maksimal } & 0,040 & 2 & 0,080 \\
\hline & 0,048 & 2 & 0,096 \\
\hline \multicolumn{4}{|l|}{ 5. Turn over staf yang tinggi di bagian operasional dan pemasaran } \\
\hline Jumlah & 1,00 & & 2,885 \\
\hline
\end{tabular}

Berdasarkan hasil dari hasil Matriks IFE di atas, diketahui bahwa faktor internal PT SNL mempunyai nilai 2,885. Menurut David (2009), berapapun banyaknya faktor yang dimasukkan dalam Matriks IFE, total nilai rata-rata tertimbang berkisar antara yang terendah 1,0 dan tertinggi 4,0, dengan rata-rata 2,5. Total nilai yang jauh di bawah 2,5 merupakan ciri organisasi yang lemah secara internal, sedangkan total nilai yang jauh di atas 2,5 menunjukkan ciri organisasi yang kuat secara internal. PT SNL dengan total nilai rata-rata tertimbang 2,885 menunjukkan strategi perusahaan dalam memanfaatkan kekuatan dan meminimalkan kelemahan berada di atas rata-rata dan kondisi internal perusahaan cenderung kuat. Untuk perhitungan Matriks EFE disajikan pada tabel berikut ini. 
Tabel 5 Matriks EFE

\begin{tabular}{|c|c|c|c|}
\hline Faktor - faktor Internal Kunci PT SNL & Bobot & Peringkat & $\begin{array}{l}\text { Rata-rata } \\
\text { tertimbang }\end{array}$ \\
\hline \multicolumn{4}{|l|}{ Peluang : } \\
\hline 1. Meningkatnya volume perdagangan global & 0,080 & 3 & 0,240 \\
\hline 2. Regulasi Pemerintah untuk meningkatkan volume export & 0,063 & 3 & 0,188 \\
\hline $\begin{array}{l}\text { 3. Terbukanya peluang kerjasama dengan mitra internasional } \\
\text { 4. Terbukanya peluang menjadi agen logistic perusahaan besar }\end{array}$ & 0,132 & 4 & 0,528 \\
\hline & 0,218 & 4 & 0,872 \\
\hline $\begin{array}{l}\text { 5. Makin meningkatnya volume export dari usaha kecil dan menengah } \\
\text { (UKM) }\end{array}$ & 0,064 & 3 & 0,193 \\
\hline \multicolumn{4}{|l|}{ Ancaman : } \\
\hline 1. Mudahnya mendirikan usaha sejenis \& masuk dalam industri & 0,090 & 1 & 0,090 \\
\hline 2. Resiko kredit macet dari pelanggan & 0,075 & 2 & 0,151 \\
\hline 3. Banyaknya perusahaan asing yang membuka cabang di Indonesia & 0,111 & 1 & 0,111 \\
\hline mendukung & 0,084 & 2 & 0,168 \\
\hline 5. Stabilitas politik antara Negara yang mengganggu bisnis transportasi & 0,083 & 1 & 0,083 \\
\hline Jumlah & 1,00 & & 2,623 \\
\hline
\end{tabular}

Berdasarkan hasil dari hasil Matriks EFE di atas, diketahui bahwa faktor eksternal PT SNL mempunyai nilai 2,623. Seperti pada matriks IFE, berapapun jumlah peluang dan ancaman utama yang dimasukkan dalam matriks EFE, total nilai rata-rata tertimbang berkisar antara yang terendah 1,0 dan tertinggi 4,0 dengan rata-rata 2,5. Walaupun nilai faktor eksternal PT SNL di atas rata-rata 2,5, PT. SNL harus tetap berupaya maksimal untuk memanfaatkan peluang eksternal dan menghindari ancaman yang dapat mempengaruhi perusahaan.

Untuk mengidentifikasi pesaing-pesaing utama PT SNL serta kekuatan dan kelemahan khusus mereka dalam hubungannya dengan posisi strategis mereka maka ditetapkan PT Real Acces dan PT Indopratama. Analisisnya dapat dilihat pada tabel berikut ini.

Tabel 6 Matriks Profil Kompetitif

\begin{tabular}{lccccccc}
\hline \multicolumn{1}{c}{$\begin{array}{c}\text { Faktor Penentu } \\
\text { Keberhasilan }\end{array}$} & \multicolumn{2}{c}{ PT SNL } & \multicolumn{2}{c}{ PT Real Acces } & \multicolumn{2}{c}{ PT Indopratama } \\
\cline { 2 - 7 } & Bobot & Peringkat & Nilai & Peringkat & Nilai & Peringkat & Nilai \\
\hline $\begin{array}{l}\text { 1. Kompetensi sumber daya } \\
\text { manusia }\end{array}$ & 0,107 & 4 & 0,429 & 4 & 0,429 & 2 & 0,214 \\
$\begin{array}{l}\text { 2. Kelengkapan jasa yang } \\
\text { ditawarkan }\end{array}$ & 0,375 & 4 & 1,501 & 4 & 1,501 & 3 & 1,126 \\
3. Network & 0,120 & 4 & 0,481 & 1 & 0,120 & 4 & 0,481 \\
4. Jumlah Pelanggan & 0,151 & 1 & 0,151 & 2 & 0,303 & 3 & 0,454 \\
5. Layanan purnajual & 0,246 & 2 & 0,492 & 2 & 0,492 & 3 & 0,738 \\
\hline \multicolumn{1}{c}{ Jumlah } & $\mathbf{1 , 0 0}$ & & $\mathbf{3 , 0 5 4}$ & & $\mathbf{2 , 8 4 5}$ & & $\mathbf{3 , 0 1 3}$ \\
\hline
\end{tabular}


Dari hasil Matriks CPM di atas, dapat diketahui bahwa total skor PT SNL adalah 3,054, sedangkan total skor untuk PT Real Acces adalah 2,845 dan PT.Indopratama adalah 3,013. Hal tersebut menunjukan bahwa posisi PT SNL masih cukup baik bila dibandingkan dengan dua pesaing utamanya. Tahap berikutnya adalah "tahap pencocokan". Dalam tahap pencocokan ini, akan digunakan beberapa metode agar dapat mendapatkan hasil strategi yang tepat untuk PT SNL. Metodemetode tersebut adalah Matriks TOWS, Matriks SPACE, Matriks IE, dan Matriks Grand Strategy.

Matriks TOWS bertujuan untuk menentukan strategi yang efektif bagi PT SNL, yang didasarkan pada kekuatan dan kelemahan yang ada, untuk menghadapi peluang dan ancaman yang datang. Matriks TOWS dapat dilihat pada Tabel 7.

\section{Tabel 7 Matriks TOWS}

\begin{tabular}{|c|c|c|}
\hline & $\begin{array}{l}\text { KEKUATAN - S } \\
\text { 1. Kompetensi sumber daya } \\
\text { manusia yang unggul dan } \\
\text { berpengalaman } \\
\text { 2. Kelengkapan jasa yang } \\
\text { ditawarkan baik kargo laut, } \\
\text { udara dan domestik } \\
\text { 3. Produk jasa tailormade yang } \\
\text { mengarah ke total logistics } \\
\text { solution } \\
\text { 4. Terdaftar dalam Gapeksi, } \\
\text { IATA dan FIATA } \\
\text { 5. Menjadi perwakilan beberapa } \\
\text { agen shipping internasional }\end{array}$ & $\begin{array}{l}\text { KELEMAHAN - W } \\
\text { 1. } \\
\text { Keterbatasan dana dalam } \\
\text { penanganan tender potensial } \\
\text { 2. Keterbatasan fasilitas } \\
\text { infrastruktur } \\
\text { 3. Kurangnya tenaga } \\
\text { pemasaran dan dana untuk } \\
\text { promosi } \\
\text { 4. Pencapaian target penjualan } \\
\text { import yang belum } \\
\text { maksimal } \\
\text { Turn over staf yang tinggi di } \\
\text { bagian operasional dan } \\
\text { pemasaran }\end{array}$ \\
\hline $\begin{aligned} \text { PELUANG - O } \\
\text { 1. } \\
\text { Meningkatnya volume } \\
\text { perdagangan global } \\
\text { 2. } \\
\text { Regulasi Pemerintah untuk } \\
\text { meningkatkan volume export } \\
\text { 3. Terbukanya peluang } \\
\text { kerjasama dengan mitra } \\
\text { internasional } \\
\text { 4. Terbukanya peluang menjadi } \\
\text { agen logistic perusahaan } \\
\text { besar } \\
\text { 5. Makin meningkatnya volume } \\
\text { export dari usaha kecil dan } \\
\text { menengah (UKM) }\end{aligned}$ & $\begin{array}{l}\text { 1. Menggarap peluang yang ada } \\
\text { dengan menawarkan jasa } \\
\text { yang fleksibel (S3, O4) } \\
\text { Strategi Pengembangan } \\
\text { Pasar }\end{array}$ & $\begin{array}{l}\text { 1. Melakukan upaya } \\
\text { peningkatan pangsa pasar } \\
\text { dengan menjalin kerja sama } \\
\text { intensif dengan para agen } \\
\text { luar negeri. (W4, O2, O3) } \\
\text { Strategi Integrasi } \\
\text { Horizontal } \\
\text { 2. Melakukan rotasi SDM } \\
\text { dengan adanya diversifikasi } \\
\text { usaha yang mengarah ke } \\
\text { total logistics solution } \\
\text { dengan menggarap pasar } \\
\text { perusahaan besar yang } \\
\text { memakai jasa outsource } \\
\text { untuk logistiknya. (W5, O4) } \\
\text { Strategi Pengembangan } \\
\text { Pasar }\end{array}$ \\
\hline $\begin{array}{ll}\text { ANCAMAN - T } \\
\text { 1. } \\
\text { Mudahnya mendirikan usaha } \\
\text { sejenis dan masuk dalam } \\
\text { industri } \\
\text { 2. } \\
\text { Resiko kredit macet dari } \\
\text { pelanggan } \\
\text { 3. } \begin{array}{l}\text { Banyaknya perusahaan asing } \\
\text { yang membuka cabang di }\end{array} \\
\text { Indonesia } \\
\text { 4. } \\
\text { Infrastruktur dan sistem } \\
\end{array}$ & $\begin{array}{l}\text { 1. Melakukan pengembangan } \\
\text { produk, tidak hanya terfokus } \\
\text { dengan ekspor general cargo, } \\
\text { tetapi menawarkan produk } \\
\text { jasa lain didukung oleh } \\
\text { produk jasa PT SNL yang } \\
\text { fleksibel. (S3, T4) Strategi } \\
\text { Pengembangan Produk } \\
\text { 2. Melakukan kerjasama atau } \\
\text { joint venture dengan para } \\
\end{array}$ & $\begin{array}{l}\text { 1. Melakukan consortium atau } \\
\text { Joint venture dengan pesaing / } \\
\text { perusahaan sejenis dan } \\
\text { mensinergikan kekuatan yang } \\
\text { dimiliki guna mendapat } \\
\text { tender - tender besar }>1 \mathrm{M} \text { ( } \\
\text { W1, T5) Strategi Integrasi } \\
\text { Horizontal } \\
\text { 2. Melakukan kerjasama atau } \\
\text { joint venture dengan para } \\
\end{array}$ \\
\hline
\end{tabular}




\begin{tabular}{|l|l|l|}
\hline \multicolumn{1}{|l|}{$\begin{array}{l}\text { birokrasi di Indonesia yang } \\
\text { kurang mendukung }\end{array}$} & $\begin{array}{l}\text { agen luar negeri untuk } \\
\text { membuka cabang jasa kurir di } \\
\text { 5. } \begin{array}{l}\text { Stabilitas politik antara } \\
\text { Negara yang mengganggu } \\
\text { bisnis transportasi }\end{array}\end{array}$ & $\begin{array}{l}\text { agen luar negeri sehingga } \\
\text { dapat mempunyai dana yang } \\
\text { Integrasi Horizontal }\end{array}$ \\
& 3. $\begin{array}{l}\text { Kontrak kerjasama dengan } \\
\text { pelanggan atau pembayaran }\end{array}$ & W3, W4, W5, T3) Strategi \\
& Integrasi Horizontal \\
& tunai ( S2, T2, T5) Strategi & \\
& Penetrasi Pasar & \\
\hline
\end{tabular}

Dari hasil analisis matriks TOWS dapat diketahui bahwa ada empat strategi yang yang dapat dijalankan, yaitu strategi pengembangan pasar, strategi integrasi horizontal, strategi pengembangan produk, dan strategi penterasi pasar. Matriks SPACE dianalisis berdasarkan faktor kekuatan keuangan, kekuatan industri, stabilitas lingkungan dan keunggulan kompetitif. Analisis Matriks SPACE dapat dilihat pada Tabel 8.

Tabel 8 Matriks SPACE

\begin{tabular}{|c|c|}
\hline 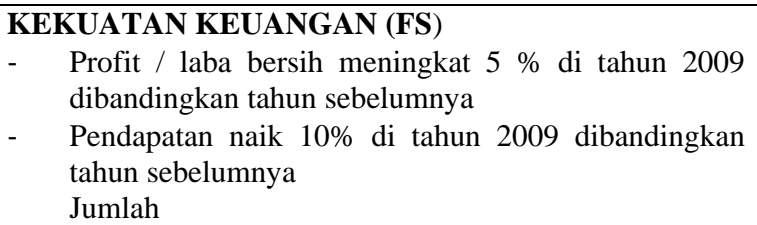 & $\begin{array}{c}\text { NILAI } \\
4\end{array}$ \\
\hline $\begin{array}{ll}\text { KEKUATAN INDUSTRI (IS) } \\
-\quad & \text { Potensi laba pada industri } \\
- & \text { Potensi pertumbuhan yang tinggi } \\
& \text { Jumlah }\end{array}$ & $\begin{array}{l}5 \\
3 \\
8\end{array}$ \\
\hline $\begin{array}{ll}\text { STABILITAS LINGKUNGAN (ES) } \\
-\quad \text { Resiko bisnis yang tinggi } \\
-\quad & \text { Tingkat inflasi yang cenderung naik } \\
\text { Jumlah }\end{array}$ & $\begin{array}{l}-3 \\
-2 \\
-5\end{array}$ \\
\hline $\begin{array}{ll}\text { KEUNGGULAN KOMPETITIF (CA) } \\
-\quad \text { Harga Bersaing } \\
- & \text { Prioritas space } \\
- & \text { Relasi dengan pemasok } \\
& \text { Jumlah } \\
\end{array}$ & $\begin{array}{l}-1 \\
-1 \\
-1 \\
-3\end{array}$ \\
\hline $\begin{array}{l}\text { KESIMPULAN } \\
\text { Rata-rata ES adalah }-5 \div 2=-2,5 \\
\text { Rata-rata CA adalah }-3 \div 3=-1 \\
\text { Rata-rata IS adalah } 8 \div 2=4 \\
\text { Rata-rata FS adalah } 8 \div 2=4 \\
\text { Sumbu x: }-1+4=3 \\
\text { Sumbu y: }-2,5+4=1,5\end{array}$ & \\
\hline
\end{tabular}

Berikut hasil matriks space PT SNL pada Gambar 1. 


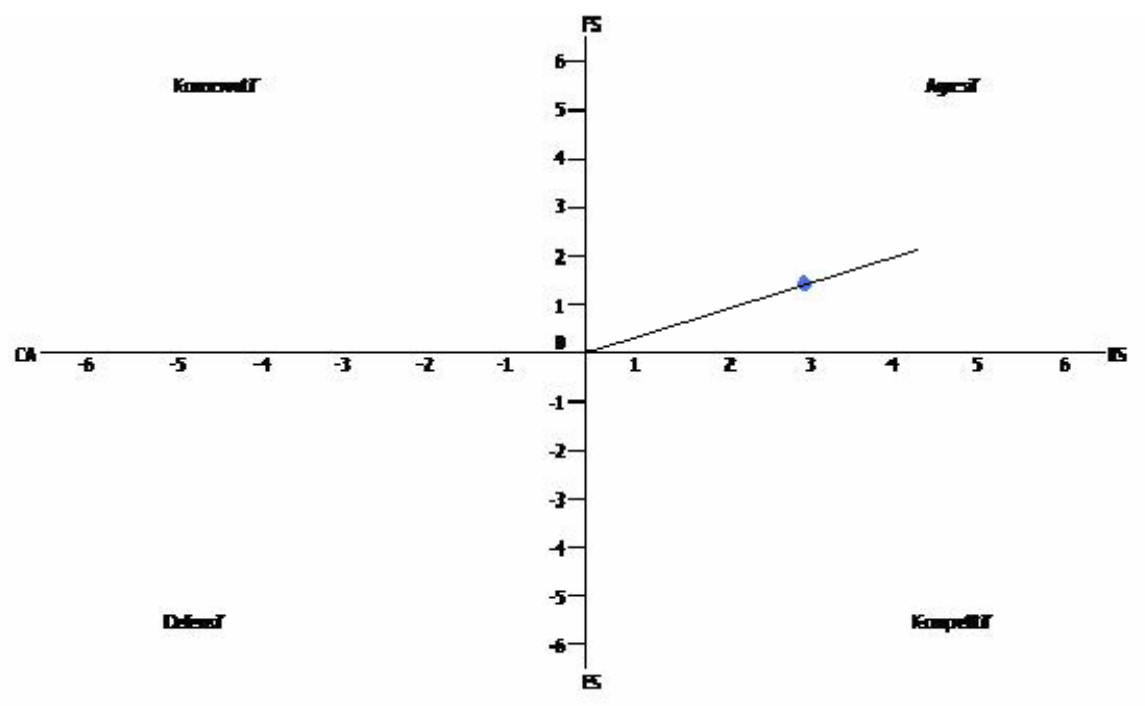

Gambar 1 Matriks Space

Dari Tabel 8 dan Gambar 1 Matrik SPACE PT SNL di atas, diketahui bahwa koordinat vektor arah pada sumbu x sebesar 3, dan pada sumbu y sebesar 1,5. Dengan demikian, dapat dilihat bahwa perusahaan berada pada kuadran agresif. Pada kuadran ini, perusahaan berada pada posisi yang baik untuk menggunakan kekuatan internalnya. Strategi yang cocok digunakan, antara lain: penetrasi pasar, pengembangan pasar, pengembangan produk, backward intergration, forward integration, horizontal integration, diversifikasi konglomerat, diversifikasi konsentrik, diversifikasi horizontal. Dilihat dari keadaan perusahaan, strategi yang bisa diterapkan: penetrasi pasar, pengembangan produk, dan backward integration.

Hasil analisis matriks Internal Eksternal dapat dilihat pada Gambar 2 berikut ini.

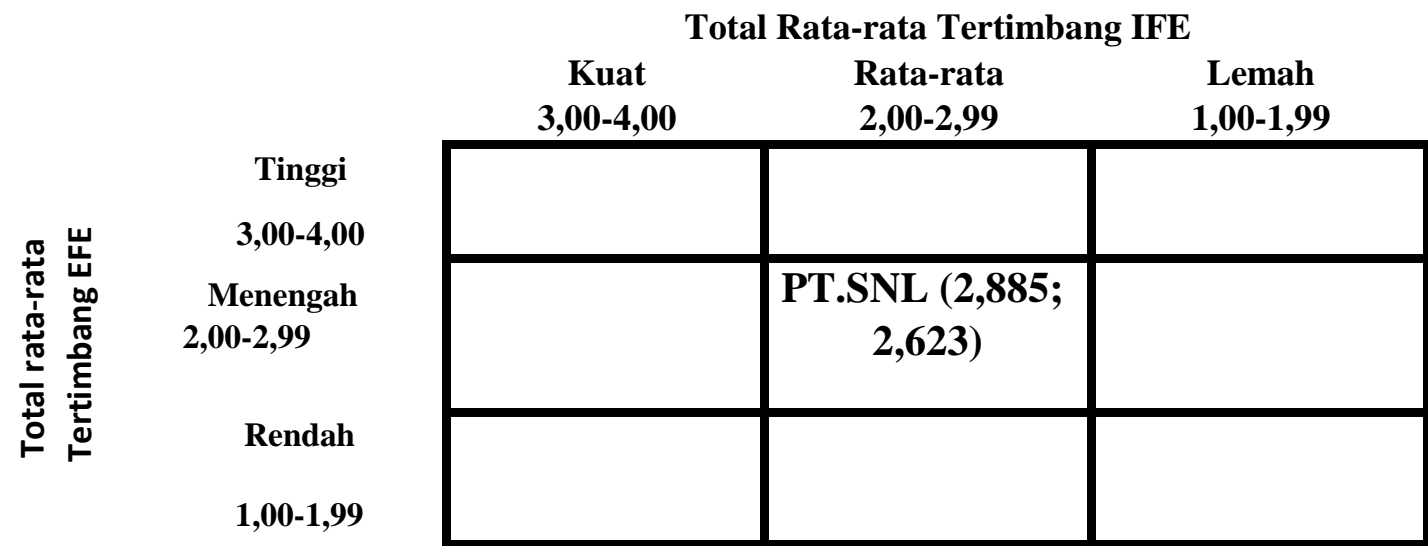

Gambar 2 Matriks Internal Eksternal

Berdasarkan hasil IFE 2,885 dan hasil EFE 2,623 yang menunjukan bahwa posisi internal maupun eksternal PT SNL bernilai sedang atau rata-rata. Dalam hasil matrik Internal-Eksternal pada Gambar 2, PT SNL berada dalam sel nomor V, yaitu dalam sel pertahankan dan pelihara. Hal tersebut merupakan suatu keadaan di mana perusahaan mengalami suatu masa pertumbuhan dan dapat dikelola 
dengan cara terbaik menggunakan strategi jaga dan pertahankan; penetrasi pasar dan pengembangan produk adalah strategi yang umum digunakan untuk perusahaan yang masuk ke sel nomor V ini. Hasil analisis dari Matriks Grand Strategy diuraikan dalam Gambar 3.

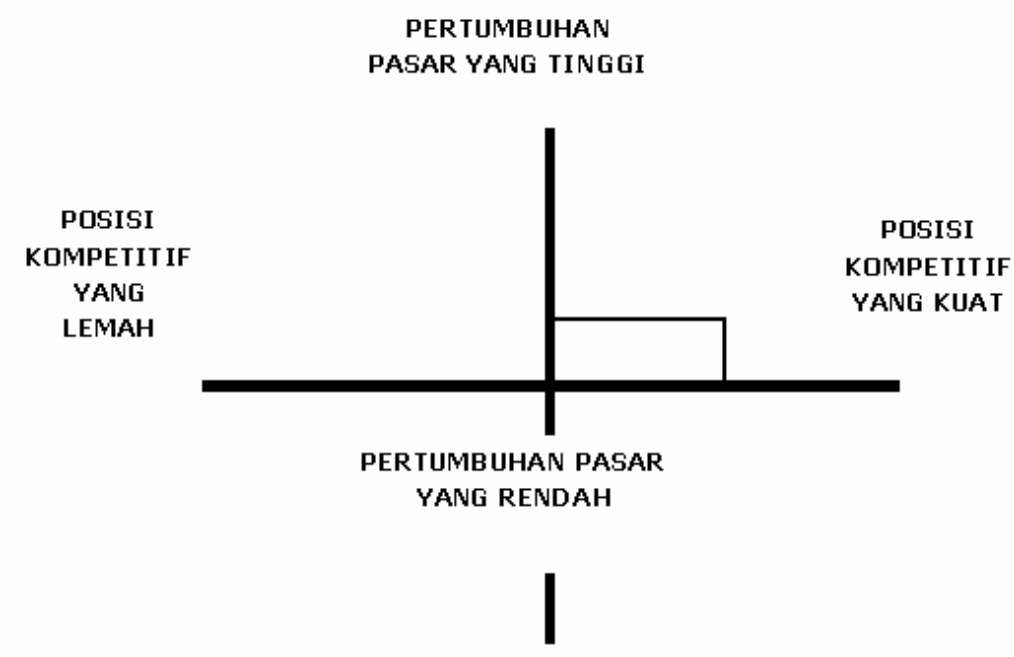

Gambar 3 Matriks Grand Strategy

Hasil Matriks Grand Strategy pada Gambar 3 menandakan bahwa posisi yang ditempati PT SNL merupakan kuadran I. Ini berarti beberapa pilihan strategi yang dapat diambil oleh perusahaan, yaitu penetrasi pasar, pengembangan pasar dan pengembangan produk. Perusahaan memiliki peluang dan kekuatan sehingga dapat memanfaatkan peluang yang ada dan mampu memanfaatkan peluang eksternal dalam banyak bidang.

Setelah melakukan analisis dan mengetahu alternatif strategi yang muncul pada tahap analisis melalui empat macam teknik, yaitu Matriks TOWS, Matriks SPACE, Matriks Internal - Eksternal dan Matriks Grand Strategy. Langkah selanjutnya adalah membuat kesimpulan tentang alternatif strategi yang paling cocok untuk dijalankan oleh PT. SNL untuk meningkatkan daya saingnya. Dalam matriks QSPM yang dapat dilihat pada tabel 9 untuk faktor internal dan tabel 10 untuk faktor eksternal, terdapat empat alternatif strategi yang dimasukkan, yaitu strategi pengembangan pasar, integrasi horizontal, pengembangan produk, dan penetrasi pasar. Keempat alternatif strategi tersebut selalu muncul dalam tahap pencocokkan.

Dalam Tabel 9, dapat dilihat bahwa total nilai daya tarik faktor internal dari strategi penetrasi pasar adalah sebesar 2,391, strategi pengembangan produk adalah sebesar 2,952, strategi integrasi horizontal adalah sebesar 2,524, dan strategi pengembangan pasar adalah sebesar 3,072. Dalam Tabel 10, dapat dilihat bahwa total nilai daya tarik faktor eksternal dari strategi penetrasi pasar adalah sebesar 1,465, strategi pengembangan produk adalah sebesar 2,972, strategi integrasi horizontal adalah sebesar 2,417, dan strategi pengembangan pasar adalah sebesar 3,005. Hasil keseluruhan matriks QSPM didapat dari penjumlahan total nilai daya tarik faktor internal dan faktor eksternal yang mana dalam Tabel 11 dapat dilihat total nilai daya tarik dari keempat alternatif strategi. Dari tabel tersebut dapat dilhat strategi mana yang daya tariknya paling besar. 
Tabel 9 Hasil QSPM Faktor Internal PT SNL

\begin{tabular}{|c|c|c|c|c|c|c|c|c|c|c|}
\hline \multirow{3}{*}{\multicolumn{2}{|c|}{ Faktor - faktor Internal Kunci PT. SNL }} & \multirow[b]{3}{*}{ ВОВОт } & \multicolumn{8}{|c|}{ ALTERNATIF STRATEGI } \\
\hline & & & \multicolumn{2}{|c|}{ Penetrasi Pasar } & \multicolumn{2}{|c|}{$\begin{array}{l}\text { Pengembangan } \\
\text { Produk }\end{array}$} & \multicolumn{2}{|c|}{ Integrasi Horizontal } & \multicolumn{2}{|c|}{$\begin{array}{l}\text { Pengembangan } \\
\text { Pasar }\end{array}$} \\
\hline & & & NDT & TNDT & NDT & TNDT & NDT & TNDT & NDT & TNDT \\
\hline \multicolumn{11}{|c|}{ Kekuatan : } \\
\hline S1 & $\begin{array}{l}\text { 1.Kompetensi sumber daya manusia yang unggul dan } \\
\text { berpengalaman }\end{array}$ & 0,068 & 2 & 0,136 & 3 & 0,204 & 2 & 0,136 & 4 & 0,272 \\
\hline S2 & $\begin{array}{l}\text { 2. Kelengkapan jasa yang ditawarkan baik kargo laut, } \\
\text { udara dan domestik }\end{array}$ & 0,224 & 3 & 0,672 & 4 & 0,896 & 2 & 0,448 & 4 & 0,896 \\
\hline S3 & $\begin{array}{l}\text { 3. Produk jasa tailormade yang mengarah ke total } \\
\text { logistics solution }\end{array}$ & 0,099 & 4 & 0,396 & 4 & 0,396 & 2 & 0,198 & 4 & 0,396 \\
\hline S4 & 4. Terdaftar dalam Gapeksi, IATA dan FIATA & 0,100 & 3 & 0,300 & 2 & 0,200 & 2 & 0,200 & 3 & 0,300 \\
\hline \multirow[t]{2}{*}{ S5 } & $\begin{array}{l}\text { 5. Menjadi perwakilan beberapa agen shipping } \\
\text { internasional }\end{array}$ & 0,161 & 3 & 0,483 & 3 & 0,483 & 4 & 0,644 & 4 & 0,644 \\
\hline & Kelemahan : & & & & & & & & & \\
\hline W1 & 1. Keterbatasan dana dalam penanganan tender potensial. & 0,153 & 1 & 0,153 & 2 & 0,306 & 4 & 0,612 & 1 & 0,153 \\
\hline W2 & 2. Keterbatasan fasilitas infrastruktur & 0,056 & 2 & 0,112 & 2 & 0,112 & 1 & 0,056 & 1 & 0,056 \\
\hline W3 & 3. Kurangnya tenaga pemasaran dan dana untuk promosi. & 0,051 & 1 & 0,051 & 1 & 0,051 & 2 & 0,102 & 1 & 0,051 \\
\hline W4 & $\begin{array}{l}\text { 4. Pencapaian target penjualan import yang belum } \\
\text { maksimal. }\end{array}$ & 0,040 & 1 & 0,040 & 4 & 0,160 & 2 & 0,080 & 4 & 0,160 \\
\hline W5 & $\begin{array}{l}\text { 5. Turn over yang tinggi di bagian operasional dan } \\
\text { pemasaran }\end{array}$ & 0,048 & 1 & 0,048 & 3 & 0,144 & 1 & 0,048 & 3 & 0,144 \\
\hline
\end{tabular}

Keterangan Tabel :

NDT = Nilai Daya Tarik TNDT $:$ Total Nilai Daya Tarik

Tabel 10 Hasil QSPM Faktor Eksternal PT SNL

\begin{tabular}{|c|c|c|c|c|c|c|c|c|c|c|}
\hline \multirow{3}{*}{\multicolumn{2}{|c|}{ Faktor - faktor Eksternal Kunci PT. SNL }} & \multirow[b]{3}{*}{ ВОВОТ } & \multicolumn{8}{|c|}{ ALTERNATIF STRATEGI } \\
\hline & & & \multicolumn{2}{|c|}{ Penetrasi Pasar } & \multicolumn{2}{|c|}{$\begin{array}{l}\text { Pengembangan } \\
\text { Produk }\end{array}$} & \multicolumn{2}{|c|}{$\begin{array}{c}\text { Integrasi } \\
\text { Horizontal }\end{array}$} & \multicolumn{2}{|c|}{$\begin{array}{l}\text { Pengembangan } \\
\text { Pasar }\end{array}$} \\
\hline & & & NDT & TNDT & NDT & TNDT & NDT & TNDT & NDT & TNDT \\
\hline \multicolumn{11}{|c|}{ Peluang : } \\
\hline $\mathrm{O} 1$ & 1. Meningkatnya volume perdagangan global & 0,080 & 1 & 0,080 & 4 & 0,320 & 2 & 0,160 & 4 & 0,320 \\
\hline $\mathrm{O} 2$ & $\begin{array}{l}\text { 2. Regulasi Pemerintah untuk meningkatkan volume } \\
\text { export }\end{array}$ & 0,063 & 1 & 0,063 & 1 & 0,063 & 1 & 0,063 & 3 & 0,189 \\
\hline $\mathrm{O} 3$ & $\begin{array}{l}\text { 3. Terbukanya peluang kerjasama dengan mitra } \\
\text { internasional }\end{array}$ & 0,132 & 3 & 0,396 & 4 & 0,528 & 2 & 0,264 & 4 & 0,528 \\
\hline $\mathrm{O} 4$ & $\begin{array}{l}\text { 4. Terbukanya peluang menjadi agen logistic } \\
\text { perusahaan besar }\end{array}$ & 0,218 & 1 & 0,218 & 4 & 0,872 & 2 & 0,436 & 4 & 0,872 \\
\hline \multirow[t]{2}{*}{ O5 } & $\begin{array}{l}\text { 5. Makin meningkatnya volume export dari usaha } \\
\text { kecil dan menengah (UKM) }\end{array}$ & 0,064 & 1 & 0,064 & 3 & 0,192 & 4 & 0,256 & 4 & 0,256 \\
\hline & Ancaman : & & & & & & & & & \\
\hline $\mathrm{T} 1$ & $\begin{array}{l}\text { 1. Mudahnya mendirikan usaha sejenis dan masuk } \\
\text { dalam industry }\end{array}$ & 0,090 & 2 & 0,180 & 2 & 0,180 & 2 & 0,180 & 2 & 0,180 \\
\hline $\mathrm{T} 2$ & 2. Resiko kredit macet dari pelanggan & 0,075 & 1 & 0,075 & 2 & 0,150 & 3 & 0,225 & 1 & 0,075 \\
\hline T3 & $\begin{array}{l}\text { 3. Banyaknya perusahaan asing yang membuka } \\
\text { cabang di Indonesia }\end{array}$ & 0,111 & 2 & 0,222 & 3 & 0,333 & 3 & 0,333 & 3 & 0,333 \\
\hline $\mathrm{T} 4$ & $\begin{array}{l}\text { 4. Infrastruktur dan sistem birokrasi di Indonesia yang } \\
\text { kurang mendukung }\end{array}$ & 0,084 & 1 & 0,084 & 2 & 0,168 & 2 & 0,168 & 3 & 0,252 \\
\hline T5 & $\begin{array}{l}\text { 5. Stabilitas politik antar Negara yang mengganggu } \\
\text { bisnis transportasi }\end{array}$ & 0,083 & 1 & 0,083 & 2 & 0,166 & 4 & 0,332 & 1 & 0,083 \\
\hline & Jumlah & 1,00 & & 1,465 & & 2,972 & & 2,417 & & 3,005 \\
\hline
\end{tabular}


Keterangan Tabel :

NDT $=$ Nilai Daya Tarik TNDT $:$ Total Nilai Daya Tarik

ini.

Rekapitulasi hasil QSPM dari total faktor internal dan eksternal dijelaskan pada tebel berikut

Tabel 11 Hasil QSPM Total Faktor Internal dan Eksternal PT SNL

\begin{tabular}{lcccc}
\hline & \multicolumn{4}{c}{ ALTERNATIF STRATEGI } \\
\cline { 2 - 5 } & $\begin{array}{l}\text { Penetrasi } \\
\text { Pasar }\end{array}$ & $\begin{array}{c}\text { Pengembangan } \\
\text { Produk }\end{array}$ & $\begin{array}{c}\text { Integrasi } \\
\text { Horizontal }\end{array}$ & $\begin{array}{c}\text { Pengembangan } \\
\text { Pasar }\end{array}$ \\
\hline $\begin{array}{l}\text { QSPM } \\
\text { FAKTOR }\end{array}$ & 2,391 & 2,952 & 2,524 & 3,072 \\
INTERNAL & 1,465 & 2,972 & 2,417 & 3,005 \\
\hline $\begin{array}{l}\text { QSPM } \\
\text { FAKTOR } \\
\text { EKTERNAL }\end{array}$ & $\mathbf{3 , 8 5 6}$ & & & $\mathbf{6 , 0 7 7}$ \\
\hline \multicolumn{1}{c}{ TOTAL } & & $\mathbf{5 , 9 2 4}$ & $\mathbf{4 , 9 4 1}$ & \\
\hline
\end{tabular}

Dari Tabel 11, terlihat bahwa dari empat alternatif strategi, jika diurutkan dari total nilai daya tarik terbesar, maka strategi pengembangan pasar adalah urutan teratas dengan total nilai daya tarik 6,077, lalu strategi pengembangan produk dengan total nilai daya tarik 5,924, kemudian strategi integrasi horizontal dengan total nilai daya tarik 4,941, dan urutan terakhir strategi penetrasi pasar dengan total nilai daya tarik 3,856.

\section{SIMPULAN}

Kekuatan utama PT SNL terletak pada kompetensi sumber daya manusia yang unggul dan berpengalaman, kelengkapan jasa yang ditawarkan baik kargo laut, udara dan domestic, produk jasa tailor made yang mengarah ke total logistics solution, terdaftar dalam Gapeksi, IATA dan FIATA, dan menjadi perwakilan beberapa agen shipping internasional. Hasil penelitian menunjukkan bahwa faktor yang sangat kuat adalah kelengkapan jasa yang ditawarkan baik kargo laut, udara dan domestik merupakan kekuatan paling besar yang paling mempengaruhi faktor internal perusahaan, sedangkan peluang pada PT SNL menurut hasil penelitian yang dilakukan adalah terbukanya peluang menjadi agen logistic perusahaan besar, di mana perusahaan dapat memanfaatkan peluang tersebut untuk meningkatkan pendapatan dan penjualan perusahaan.

Berdasarkan Matriks IFE, diperoleh total skor sebesar 2,885. Nilai tersebut menandakan bahwa perusahaan sudah mempunya strategi yang relatif baik dalam mengantisipasi kelemahan internal dan mengoptimalkan kekuatan yang ada. Sedangkan untuk Matriks EFE, diperoleh total skor sebesar 2,623. Nilai tersebut menandakan bahwa perusahaan sedikit mampu dalam mengatasi hambatan-hambatannya. Perusahaan juga mempunyai kemampuan yang relatif baik untuk meraih peluang yang ada. Selanjutnya hasil pengolahan data-data dan informasi menggunakan matriks TOWS dapat diketahui bahwa perusahaan sebaiknya menggunakan strategi pengembangan pasar, strategi integrasi horizontal, strategi pengembangan produk, dan strategi penetrasi pasar. Hasil pengolahan data Matriks IE dan SPACE diketahui bahwa alternatif strategi yang baik untuk PT SNL adalah strategi intensif, yakni strategi penetrasi pasar, pengembangan produk, dan integrasi horizontal. Hasil analisis matriks Grand Startegy, perusahaan berada pada kuadran I di mana perusahaan berada pada 
posisi persaingan yang yang relatif kuat dan dilihat dari kondisi bisnis saat ini perusahaan berada dalam pertumbuhan pasar yang cepat. Berdasarkan hal tersebut, perusahaan dapat melakukan pengembangan pasar, pengembangan produk, dan integrasi horizontal. Dari hasil analisis matriks QSPM, strategi yang tepat yang dapat dijalankan untuk PT SNL adalah dengan melakukan pengembangan pasar, yang diikuti dengan melakukan pengembangan produk. Dari hasil studi tentang perumusan strategi perusahaan yang telah dipaparkan pada penelitian ini, diharapkan akan turut mendorong kajian lebih mendalam tentang bidang manajemen strategi, khususnya dalam bidang perumusan strategi perusahaan.

\section{DAFTAR PUSTAKA}

Barney, Jay B. (2007). Gaining and sustaining competitive advantage, $3^{\text {rd }}$ ed., New Jersey: Pearson Prentice Hall.

Biro Pusat Statistik. (2010). Pertumbuhan ekonomi Indonesia triwulan III 2009. Diakses 2 Maret 2010 dari http://www.bps.go.id/brs_file/pdb-10nov09.pdf.

Cravens, D. W. (2008). Strategic marketing, $9^{\text {th }}$ ed., United States of America: McGraw Hill Higher Education.

David, F. R. (2009). Strategic management, $12^{\text {th }}$ ed., New Jersey: Pearson Prentice Hall.

Grant, R. M. (1991). The resource base theory of competitive advantage, California dalam Journal Management Review, (2010); 33 (3), 114-135.

Hitt, Michael A, et al. (2001). Strategic management-competitiveness and globalization, $4^{\text {th }}$ ed., United States of America: Thomson Learning.

Kaplan and Norton. (2008). The execution premium: Linking strategy to operation for competitive, Boston: Harvard Business School Publishing Corporation.

Lindelof, P., and Hans Lofsten. (2004). Proximity as a resource base for competitive advantage: university-industry links for technology transfer. Dalam Journal of Technology Transfer, 29, 34, (Online), August 2009.

Porter, M. E. (1998). On competition, Boston : Harvard Business School Publishing Corporation.

Rangkuti, F. (1998). Analisis SWOT teknik membedah kasus bisnis, Jakarta: PT Gramedia.

Sugiono. (2003). Metode penelitian bisnis, cetakan pertama, Bandung: Alfabeta.

Walker, G. (2007). Modern competitive strategy, $2^{\text {nd }}$ ed., New York: The Mc.Graw Hill Companies, Inc.

Wheelen, T. L., and Hunger J. D. (2001). Strategic management and business policy, $5^{\text {th }}$ ed., United States of America: Addison-Wesley Publishing Company.

Winardi. (2003). Kreativitas dan teknik-teknik pemikiran kreatif dalam bidang manajemen, Bandung: Citra Aditya.

Yuwono, S., dan Ichsan. (2007). Petunjuk praktis penyusunan Balanced Scorecard, menuju organisasi yang berfokus pada srategi, cetakan kelima, Jakarta: PT Gramedia Pustaka Utama. 